\title{
Cigarette smoking in women after BRCA1/2 genetic test disclosure: a 5-year follow-up study of the GENEPSO PS cohort
}

\author{
Claire Julian-Reynier, $\mathrm{MD}, \mathrm{MSc}^{1-3}$, Noémie Resseguier, $\mathrm{MD}, \mathrm{PhD}^{2,3}$, \\ Anne-Deborah Bouhnik, MSc, PhD 2,3, François Eisinger, $\mathrm{MD}^{1-3}$, Christine Lasset, MD, PhD ${ }^{4}$, \\ Emmanuelle Fourme, $\mathrm{MD}^{5,6}$ and Catherine Noguès, $\mathrm{MD}^{5,6}$
}

\begin{abstract}
Purpose: This study aimed to measure patients' smoking patterns for 5 years after $B R C A 1 / 2$ test result disclosure.

Methods: A national cohort consisting of 621 French cancer-free women from families with $B R C A 1 / 2$ mutations (mean age (SD): 40.5 years (11.5 years)) were included from December 1999 to January 2006, before disclosure of genetic test results, and followed for 5 years. They completed self-administered questionnaires about their cigarette smoking behaviors before receiving their test results (baseline) and 6, 12, 24, and 60 months after disclosure. Multivariate statistical analyses of the changes in participants' smoking behaviors were performed using a zero-inflated Poisson mixed model.
\end{abstract}

Results: Baseline smoking was found to depend on age, educational level, marital status, alcohol consumption, body mass index, and cancer risk perception. The zero-inflated part of the model showed the occurrence of no significant changes in the percentage of smokers during the 5 years after disclosure of the $B R C A 1 / 2$ test results; however, daily smoking among $B R C A 1 / 2$ carriers decreased significantly compared with that of noncarriers (adjusted hazard ratio = 0.83; (95\% confidence interval: 0.69-0.99); $P=0.04$ ) after adjusting for baseline smoking behavior.

Conclusion: It would be worth investigating the possibility of counseling women during the genetic testing process about the multiple risk factors involved in cancer, such as genetic and lifestyle factors.

Genet Med advance online publication 10 July 2014

Key Words: $B R C A 1 / 2$; breast cancer; cancer genetic testing; prevention; smoking behavior

\section{INTRODUCTION}

The benefits of giving up smoking have been constantly stressed, especially in the case of women, among whom smoking rates have been increasing. ${ }^{1}$ Two-thirds of all deaths of women smokers in the United Kingdom are caused by smoking in their 50s, $60 \mathrm{~s}$, and $70 \mathrm{~s},{ }^{1}$ and the figures are likely to be similar in other industrialized countries. ${ }^{2}$ Breast cancer was recently included among the 30 most common specific causes of death among smokers, ${ }^{1}$ and it is emerging that smoking before first childbirth may also be one of the specific risk factors involved. ${ }^{3}$ Breast cancer is by far the most frequent form of cancer occurring among women-it accounts for $23 \%$ of all cases of cancer in womenand ranks second overall (10.9\% of all cases of cancer in both sexes combined). ${ }^{2}$ In female $B R C A 1 / 2$ carriers, smoking may increase the risk of breast cancer, especially when the mutations are located in specific sites. ${ }^{4-6}$

Several authors have studied the effects of the disclosure of $B R C A 1 / 2$ genetic test results on specific strategies for preventing breast/ovarian cancer, such as breast cancer screening and prophylactic surgery. ${ }^{7-9}$ Although women's screening practices have been found to correlate with their families' history of breast cancer, the lifestyle risk factors seem to be similar to those of women with no family history of cancer. ${ }^{10,11}$ Little information is available about the lifestyle habits of $B R C A 1 / 2$ carriers after the disclosure of genetic test results. Preliminary findings have shown that women applying for genetic testing may have better health-related practices than members of the general population. ${ }^{12}$

The aim of this prospective study was to measure the smoking habits of cancer-free women who applied for genetic testing because a BRCA1/2 mutation had been identified in their family and to identify the potential determinants of any changes in their smoking rates over time, such as their medical, genetic, sociodemographic, and psychological characteristics. To our knowledge, no previous studies have focused on this issue.

\section{MATERIALS AND METHODS}

Study population and study sample

In the framework of the ongoing French national Gene Etude Prospective Sein Ovaire (GENEPSO) project, managed by the French Cancer Genetic Network, cancer-free BRCA1/2 mutation carriers were recruited in a routine consultation context at

\footnotetext{
${ }^{1}$ Institut Paoli-Calmettes, UMR912, Marseille, France; ${ }^{2}$ INSERM, UMR912, Economics and Social Sciences Applied to Health \& Analysis of Medical Information (SESSTIM), Marseille, France; ${ }^{3}$ Aix-Marseille University, UMR_S912, IRD, Marseille, France; ${ }^{4}$ Centre Léon Bérard, Lyon, France; ${ }^{5}$ Hôpital René Huguenin, Saint Cloud, France; ${ }^{6}$ Institut Curie, Paris, France. Correspondence: Claire Julian-Reynier (claire.julian-reynier@inserm.fr)
} 
cancer genetic clinics between 2000 and 2006. Non-mutation carriers from families in which a $B R C A 1 / 2$ mutation had been identified were included as well as unaffected carriers, and both groups constituted the GENEPSO PsychoSocial (PS) cohort. Cancer-free women were then recruited and included before disclosure of their genetic test results, and they were subsequently followed for 5 years. Any incident breast/ovarian cancer cases $(n=22)$ were excluded from the statistical analyses as soon as cancer was detected.

\section{Data collection}

Self-administered questionnaires were filled out by the women at various follow-up times: the first baseline questionnaire was completed at the cancer genetic clinic just before disclosure of the genetic test results (questionnaire $\mathrm{Q}_{\mathrm{M} 0}$ ), and four other questionnaires were mailed to participants homes and completed 6, 12, 24, and 60 months after delivery of the results (in questionnaires $\mathrm{Q}_{\mathrm{M} 6}, \mathrm{Q}_{\mathrm{M} 12}, \mathrm{Q}_{\mathrm{M} 24}$, and $\mathrm{Q}_{\mathrm{M} 60}$, respectively). Cancer geneticists completed an inclusion form providing baseline medical information and clinical follow-up data on the carriers. The study was approved by the French National Commission for Data Protection and Privacy (Commission Nationale de l'Informatique et des Libertés).

\section{Assessment of smoking}

The dependent variable studied here was the declared cigarette consumption rate, expressed as the average number of cigarettes smoked per day at the time the questionnaire was completed. This variable was quantified before and after disclosure of the participants' genetic test results (in questionnaires $\mathrm{Q}_{\mathrm{M} 0}$, $\mathrm{Q}_{\mathrm{M} 6}, \mathrm{Q}_{\mathrm{M} 12}, \mathrm{Q}_{\mathrm{M} 24}$, and $\left.\mathrm{Q}_{\mathrm{M} 60}\right)$.

\section{Assessment of medical, sociodemographic, and psychobehavioral characteristics}

Medical variables collected in the baseline medical questionnaire included body mass index, BRCA1/2 mutation carrier status, and occurrence of risk-reducing mastectomy during the follow-up period. Sociodemographic variables collected in the baseline questionnaire included age, level of education, marital status, and occupational activity.

Psychological and behavioral variables included cancer risk perception (other than the breast and ovarian cancer risks) and the participants' alcohol consumption. The presence of highly depressive symptoms at each point during the follow-up period was assessed using the French version of the Center for Epidemiologic Studies Depression scale, ${ }^{13,14}$ which consists of 20 items generating scores of $0,1,2$, or 3 . The overall score was dichotomized using the value of 23 as a cutoff point, as previously recommended for identifying French women with highly depressive symptoms. ${ }^{13,14}$

\section{Statistical analysis}

Data were recorded and checked for consistency before statistical analysis using SAS 9.3 software (SAS Institute, Cary, NC) was performed. The characteristics of the study sample were described in the study population as a whole and in two subsamples defined in terms of whether they participated. Only women who had declared their cigarette consumption practices before delivery of their BRCA1/2 mutation test results, including nonsmokers, and subsequently answered these same questions at least once during the follow-up period were eligible to participate and were included in the statistical analysis.

The participants' smoking patterns (expressed as the number of cigarettes smoked per day) before delivery of their genetic test results were analyzed as a dependent variable depending on individual characteristics using a zero-inflated Poisson (ZIP) regression model. ${ }^{15-17}$ The ZIP model can be used to deal with data with a mixed distribution: a binomial distribution to deal with the zero versus nonzero groups (i.e., nonsmokers versus smokers in this case) and a Poisson distribution to deal with the nonzero part of the distribution (i.e., the number of cigarettes smoked among the smokers in this case). Various sets of covariates were included in this model-one for the binomial process and one for the Poisson process - which is particularly suitable in the context of studies of the determinants of smoking behavior because it can be assumed that some characteristics may be associated only with either smoker/nonsmoker status or smokers' consumption of cigarettes.

The cigarette smoking pattern over time was analyzed as a dependent variable depending on individual characteristics, using a random effect mixed ZIP regression model. Our model was therefore designed to take into account the intraindividual correlations possibly involved in the participants' smoking behavior (the subject effect was taken to be a random effect in both parts of the ZIP model). The full model included all the preselected variables identified as potential determinants of the participants' smoking practices over time, and, after adjusting for forced covariates (age, time, smoking before disclosure of the genetic test results), a backward-selection procedure was applied to select the significant independent variables $(P<$ 0.05). Akaike and Bayesian information criteria were used to determine the final model. We did not impute missing data at follow-up; the use of a model for repeated measures enabled us to include a maximum amount of information in the presence of missing data at follow-up. ${ }^{18}$ We compared the 5-year respondents/nonrespondents' previous tobacco consumption measurements $\left(\mathrm{Q}_{\mathrm{M} 6}, \mathrm{Q}_{\mathrm{M} 12}, \mathrm{Q}_{\mathrm{M} 24}\right)$ to check that we had not lost the heaviest smokers.

\section{Sensitivity analysis}

Two sensitivity analyses of the data were performed, first because nonparticipants had higher cigarette consumption rates at baseline (Table 1), and second because women who had undergone risk-reducing mastectomy might have been advised by their health-care providers to refrain from smoking before breast reconstruction, for medical reasons. ${ }^{19}$ In the first sensitivity analysis, the missing follow-up smoking characteristics were imputed using the last observation carried forward approach; and the 30 women who underwent risk-reducing mastectomy were excluded from the second sensitivity analysis. 
Table 1 Characteristics of participants versus nonparticipants $(N=621)$

\begin{tabular}{|c|c|c|c|c|c|c|c|}
\hline & Tota & $=621)$ & Particip & $(n=580)$ & Nonparti & nts $(n=41)$ & \\
\hline & $\begin{array}{c}\text { Number/ } \\
\text { mean }\end{array}$ & $\% / S D$ & $\begin{array}{c}\text { Number/ } \\
\text { mean }\end{array}$ & $\% / S D$ & $\begin{array}{c}\text { Number/ } \\
\text { mean }\end{array}$ & $\% / S D$ & $\begin{array}{c}P \\
\text { value }^{a}\end{array}$ \\
\hline Age & 40.52 & 11.53 & 40.60 & 11.67 & 39.41 & 9.47 & 0.525 \\
\hline$\leq$ High school diploma & 271 & $43.6 \%$ & 254 & $43.8 \%$ & 17 & $41.5 \%$ & \\
\hline >High school diploma & 346 & $55.7 \%$ & 322 & $55.5 \%$ & 24 & $58.5 \%$ & \\
\hline Nonactive & 147 & $23.7 \%$ & 142 & $24.5 \%$ & 5 & $12.2 \%$ & \\
\hline Active & 472 & $76.0 \%$ & 437 & $75.3 \%$ & 35 & $85.4 \%$ & \\
\hline NA & 2 & $0.3 \%$ & 1 & $0.2 \%$ & 1 & $2.4 \%$ & \\
\hline Married or living with a partner & & & & & & & 0.236 \\
\hline No & 136 & $21.9 \%$ & 124 & $21.4 \%$ & 12 & $29.3 \%$ & \\
\hline No & 362 & $58.3 \%$ & 341 & $58.8 \%$ & 21 & $51.2 \%$ & \\
\hline Yes & 259 & $41.7 \%$ & 239 & $41.2 \%$ & 20 & $48.8 \%$ & \\
\hline $\begin{array}{l}\text { Presenting with highly depressive } \\
\text { symptoms }\end{array}$ & & & & & & & 0.244 \\
\hline No & 533 & $85.8 \%$ & 496 & $85.5 \%$ & 37 & $90.2 \%$ & \\
\hline Yes & 84 & $13.5 \%$ & 81 & $14.0 \%$ & 3 & $7.3 \%$ & \\
\hline NA & 4 & $0.6 \%$ & 3 & $0.5 \%$ & 1 & $2.4 \%$ & \\
\hline $\begin{array}{l}\text { Perception of risk for cancer (other } \\
\text { than breast and ovarian) }\end{array}$ & & & & & & & 0.944 \\
\hline Zero to medium & 528 & $85.0 \%$ & 493 & $85.0 \%$ & 35 & $85.4 \%$ & \\
\hline Number of cigarettes smoked & & & & & & & 0.014 \\
\hline Zero & 451 & $72.6 \%$ & 437 & $75.3 \%$ & 14 & $34.1 \%$ & \\
\hline More than zero & 155 & $25.0 \%$ & 143 & $24.7 \%$ & 12 & $29.3 \%$ & \\
\hline NA & 15 & $2.4 \%$ & 0 & $0.0 \%$ & 15 & $36.6 \%$ & \\
\hline Among all participants & 2.63 & 5.95 & 2.45 & 5.71 & 6.65 & 9.17 & 0.029 \\
\hline Among current smokers & 10.28 & 7.76 & 9.93 & 7.64 & 14.42 & 8.32 & 0.054 \\
\hline
\end{tabular}

BMI, body mass index; NA, not available.

aln the case of qualitative variables, $\chi^{2}$ tests were performed on valid numbers.

\section{RESULTS}

\section{Sample characteristics}

During the study period (2000-2006), 621 women were included in the GENEPSO PS cohort, 580 (93.4\%) of whom participated in the current follow-up study. Baseline descriptive characteristics of the participants and nonparticipants are presented in Table 1. The two groups were similar in terms of all the characteristics tested, except for their smoking habits. Nonparticipants smoked more frequently and more intensively than participants $(P<0.01)$.

\section{Baseline smoking characteristics}

The characteristics of the baseline smoking patterns (before delivery of genetic test results) are presented in Table 2. According to the multivariate analysis and the zero-inflated part of the model, the probability of being a nonsmoker was associated with older age $(P<0.001)$ and lower alcohol consumption $(P=0.006)$. A lower cigarette consumption ratio (among smokers; the Poisson part of the model) was associated with having a higher level of education $(P<0.001)$, not being married $(P=$ 0.007 ), and having a lower perception of risk for cancer other 


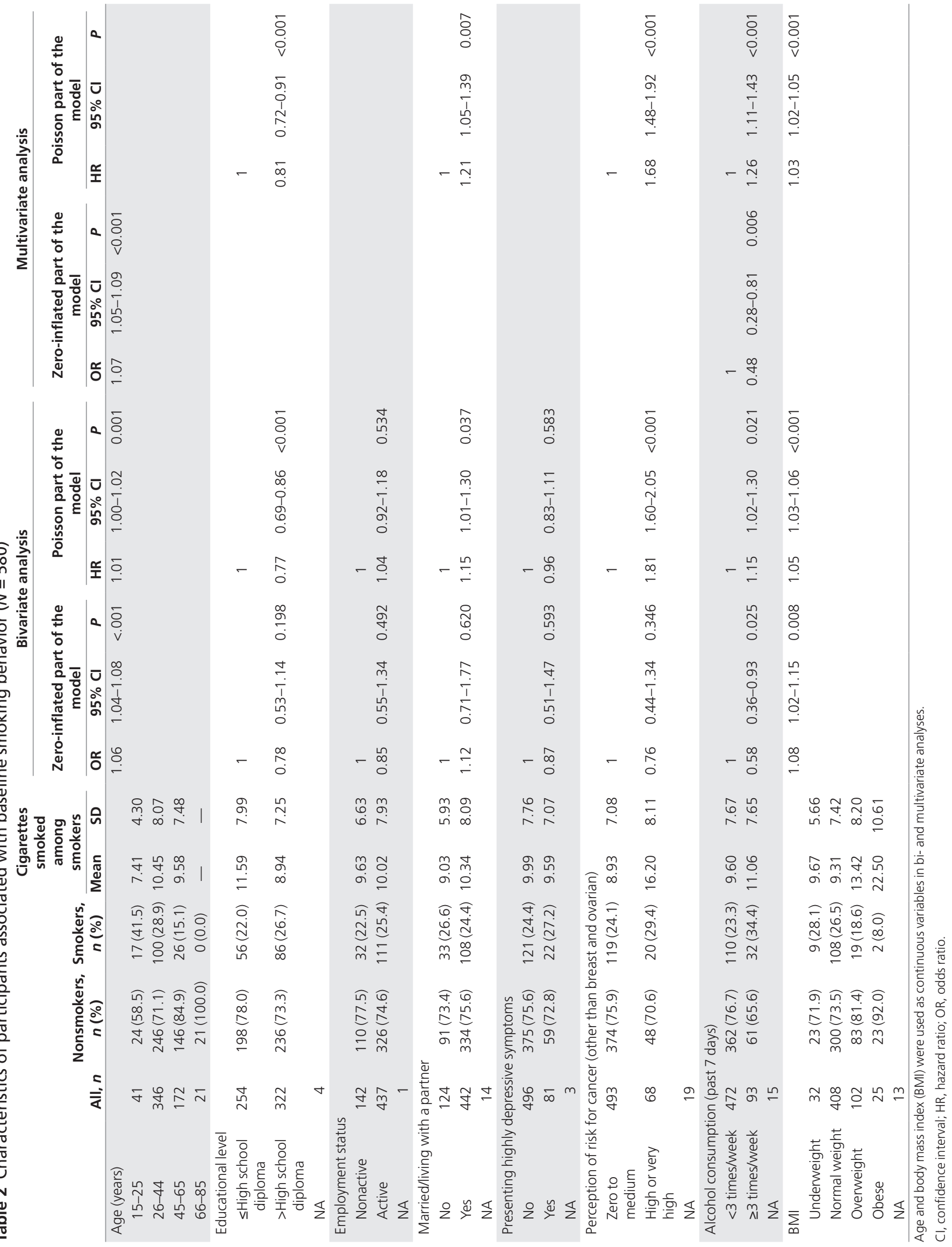


Table 3 Cigarette smoking rates over time, depending on $B R C A 1 / 2$ mutation status $(N=580)$

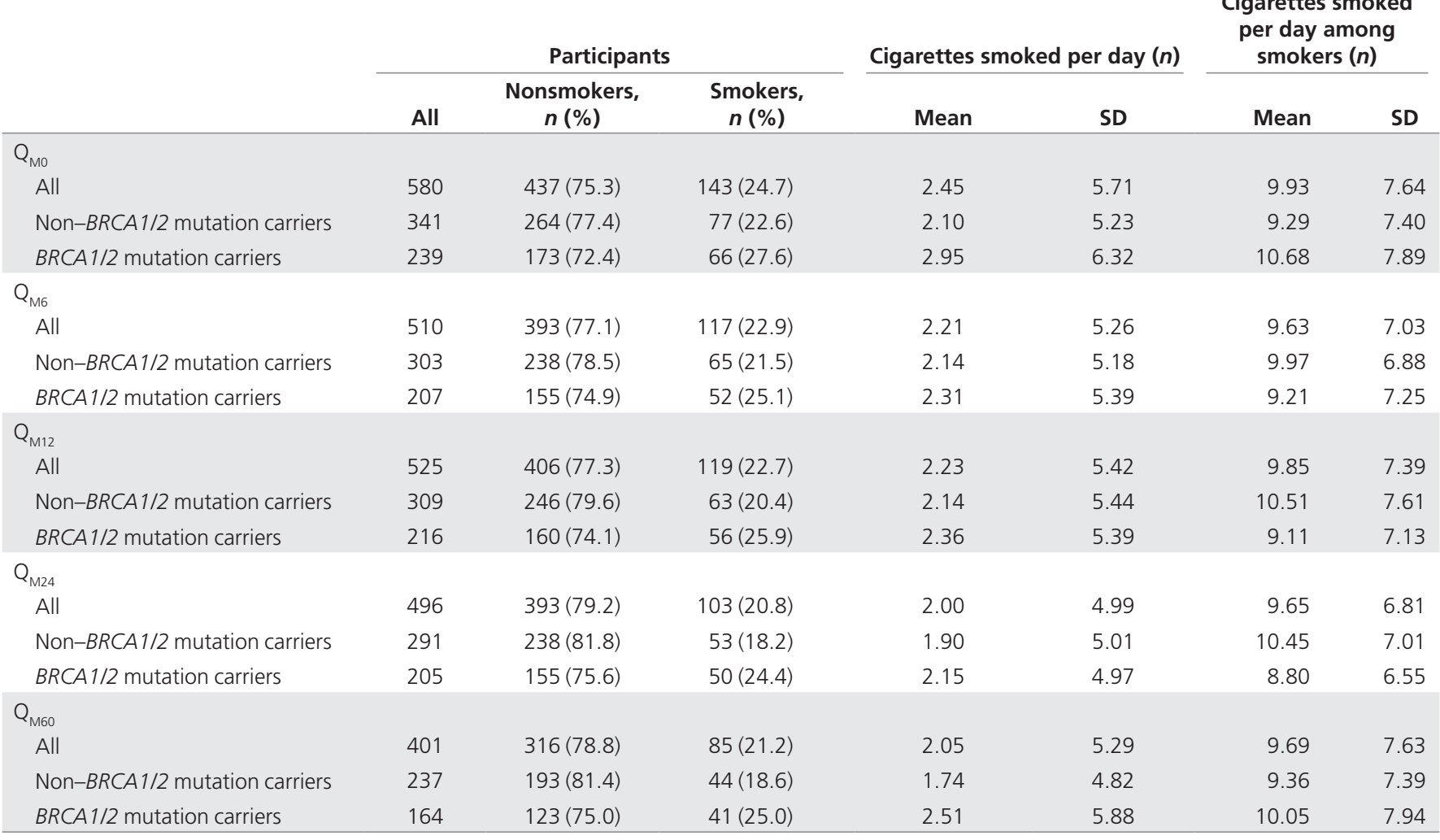

than breast/ovarian cancer $(P<0.001)$, a lower ratio of alcohol consumption $(P<0.001)$, and a lower body mass index $(P<$ $0.001)$.

\section{Factors determining changes in smoking behavior}

The observed patterns of smoking behavior over time depending on BRCA1/2 mutation status showed that the percentage of smokers generally remained stable and that the mean cigarette consumption decreased in BRCA1/2 carriers (Table 3 ). In $B R C A 1 / 2$ carriers, the number of cigarettes smoked per day showed a clear-cut decrease 2 years after disclosure, but it tended to increase again 5 years after disclosure. The factors determining the changes in smoking habits with time are presented in Table 4 (bivariate analyses) and Table 5 (multivariate analyses). In the mixed bivariate ZIP regression analysis, each covariate was included in both parts of the model (the binomial part and the Poisson part), along with forced covariates (age, time, cigarette consumption before disclosure of genetic test results, and random effects). After adjusting for forced covariates, being a BRCA1/2 mutation carrier was the only characteristic found to be significantly associated with the Poisson part of the model (adjusted hazard ratio $=0.83 ; 95 \%$ confidence interval: $0.69-0.99 ; P=0.043$ ). Depressive symptoms, age, and alcohol consumption included in the ZIP models were the variables collected at each time of the prospective follow-up. The comparisons between the 5-year respondents and nonrespondents did not show the existence of any differences in terms of tobacco consumption from $\mathrm{Q}_{\mathrm{M} 0}$ to $\mathrm{Q}_{\mathrm{M} 24}$. This means that the
$30 \%$ of the participants who did not complete the $\mathrm{Q}_{\mathrm{M} 60}$ were not heavier smokers than the others.

Because nonparticipants had consumed more cigarettes at baseline (Table 1), a sensitivity analysis was carried out on this group. The above association was still found to be significant $(N=606$; adjusted hazard ratio $=0.83 ; 95 \%$ confidence interval: $0.70-0.98 ; P=0.030$ ).

Because risk-reducing mastectomy/breast reconstruction may incite women to smoke less, another sensitivity analysis, excluding the 30 women who underwent this intervention, was carried out. The above association was still found to be significant (adjusted hazard ratio $=0.82 ; 95 \%$ confidence interval: $0.67-0.99 ; P=0.041)$.

\section{DISCUSSION}

This is the first prospective study of the smoking habits of unaffected BRCA1/2 carriers/noncarriers during the 5 -year period after their BRCA1/2 test results were disclosed. This study shows that no change in the prevalence of smokers occurred after disclosure of the participants' BRCA1/2 test results. The most noteworthy finding after adjusting for the participants' baseline cigarette consumption practices was that the number of cigarettes smoked per day by BRCA1/2 carriers decreased significantly compared with that of the noncarriers. Mutation status was the only significant predictor of behavioral change. Baseline smoking was found to depend on age, educational level, marital status, alcohol consumption, body mass index, and cancer risk perception. 
Table 4 Bivariate statistical analysis of the determinants of smoking behavior with time $(N=580)$

\begin{tabular}{|c|c|c|c|c|c|c|c|}
\hline & \multirow{2}{*}{ Number ${ }^{a}$} & \multicolumn{6}{|c|}{ Bivariate analysis } \\
\hline & & \multicolumn{3}{|c|}{ Zero-inflated part of the model } & \multicolumn{3}{|c|}{ Poisson part of the model } \\
\hline \multicolumn{8}{|l|}{ Educational level } \\
\hline >High school diploma & 322 & 2.56 & $0.77-8.45$ & 0.124 & 0.92 & $0.76-1.12$ & 0.408 \\
\hline \multicolumn{8}{|l|}{ Employment status } \\
\hline \multicolumn{8}{|c|}{ Married or living with a partner } \\
\hline No & 124 & 1 & & & 1 & & \\
\hline Yes & 442 & 1.46 & $0.41-5.18$ & 0.562 & 0.89 & $0.71-1.11$ & 0.304 \\
\hline \multicolumn{8}{|l|}{ BRCA1/2 mutation carrier } \\
\hline Yes & 81 & 1.67 & $0.34-8.11$ & 0.523 & 1.07 & $0.83-1.39$ & 0.591 \\
\hline \multicolumn{8}{|c|}{ Perception of risk for cancer (other than breast and ovarian) } \\
\hline Zero to medium & 493 & 1 & & & 1 & & \\
\hline High or very high & 68 & 0.23 & $0.05-0.94$ & 0.041 & 1.24 & $0.96-1.60$ & 0.101 \\
\hline \multicolumn{8}{|c|}{ Alcohol consumption (past 7 days) } \\
\hline$<3$ Times/week & 472 & 1 & & & 1 & & \\
\hline$\geq 3$ Times/week & 93 & 1.07 & $0.36-3.13$ & 0.905 & 1.08 & $0.95-1.22$ & 0.261 \\
\hline Body mass index & 567 & 0.94 & $0.82-1.08$ & 0.374 & 1.00 & $0.97-1.03$ & 0.902 \\
\hline
\end{tabular}

$\mathrm{Cl}$, confidence interval; $\mathrm{HR}$, hazard ratio; $\mathrm{OR}$, odds ratio.

aNumbers correspond to baseline characteristics.

As far as we know, the preventive information delivered in the context of cancer genetic clinics is risk specific and does not cover the major cancer risk factors, especially lifestyle risk factors such as smoking. ${ }^{20}$ Here, we assumed that the disclosure of cancer genetic test results may affect cancer worry and risk perception and thus prompt patients to spontaneously take multiple cancer risk-reduction measures. This assumption turned out to be only partly true-no changes were observed in the prevalence of smokers/nonsmokers during the 5 years that elapsed after disclosure of the cancer genetic test results. However, the number of cigarettes smoked per day by BRCA1/2 carriers decreased significantly in comparison with that of noncarriers, although the former group's smoking practices tended to increase again at the 5 -year assessment. Although this decrease was statistically significant, its clinical significance was marginal and does not seem likely to have decreased the risk of cancer in this study population. It is worth noting that the baseline prevalence of cigarette smokers in the cohort (25\%) was comparable to that observed in the corresponding French female population at the time of the survey. ${ }^{21}$ Our participants' weight ${ }^{22}$ and alcohol consumption characteristics also were comparable to those of the general French female population in this age group. ${ }^{23}$
Table 5 Multivariate statistical analysis of the determinants of smoking behavior over time $(N=580)$

\begin{tabular}{|c|c|c|c|}
\hline $\begin{array}{l}\text { Zero-inflated part of } \\
\text { the model }\end{array}$ & AOR & $95 \% \mathrm{Cl}$ & $P$ value \\
\hline \multicolumn{4}{|l|}{ Current smoker at $\mathrm{Q}_{\mathrm{M} 0}$} \\
\hline No & 1 & & \\
\hline Yes & $<0.01$ & $<0.01-<0.01$ & $<0.001$ \\
\hline Age (years) & 1.05 & $0.99-1.10$ & 0.085 \\
\hline Time (months) & 1.01 & $0.99-1.02$ & 0.274 \\
\hline Random effect ${ }^{a}$ & & & $<0.001$ \\
\hline $\begin{array}{l}\text { Poisson part of the } \\
\text { model }\end{array}$ & AHR & $95 \% \mathrm{Cl}$ & $P$ value \\
\hline 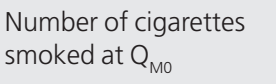 & 1.08 & $1.07-1.09$ & $<0.001$ \\
\hline Age (years) & 1.00 & $0.99-1.01$ & 0.471 \\
\hline Time (months) & 1.00 & $1.00-1.00$ & 0.410 \\
\hline \multicolumn{4}{|l|}{ BRCA1/2 mutation carrier } \\
\hline No & 1 & & \\
\hline Yes & 0.83 & $0.69-0.99$ & 0.043 \\
\hline Random effect ${ }^{a}$ & & & $<0.001$ \\
\hline
\end{tabular}

AHR, adjusted hazard ratio; $A O R$, adjusted odds ratio; $\mathrm{Cl}$, confidence interval; $\mathrm{Q}_{\mathrm{M} 0^{\prime}}$ baseline questionnaire.

${ }^{\text {aC }}$ Covariance between the random effects of the two parts of the model $(P=0.024)$. 
It seemed likely that $B R C A 1 / 2$ test result disclosure might prompt carriers to make behavioral changes, such as reducing their cigarette consumption, in order to decrease their overall risk of cancer. The statistically significant decrease observed here in BRCA1/2 carriers' daily smoking rates suggests that in the future it might be possible to discourage women from smoking in the context of genetic tests. Proactive antismoking approaches such as those recently promoted ${ }^{24}$ might have positive effects on these populations if they are applied during the process of disclosing genetic test results. Because smoking in women is becoming a serious public health issue, and because it is so difficult to change people's smoking habits, ${ }^{25}$ this possibility would be worth investigating further, in line with previous studies in other medical contexts, using suitable experimental procedures for assessing the long-term impact of multiple risk-prevention interventions on populations of young women at risk. The term "teachable moment" has been used to suggest that health events can be powerful motivators for health-improving changes, promoting healthy habits and discouraging unhealthy ones, ${ }^{26,27}$ especially in primary-care settings ${ }^{28}$; this could also be one of the new goals of the comprehensive educational programs currently being developed in the field of genomic testing. In the context of smoking, three criteria for determining whether a cueing event is significant enough to be a teachable moment have been proposed: the extent to which the event increases people's personal risk perceptions and outcome expectancies, the extent to which the event prompts strong affective or emotional responses, and the extent to which the event redefines the self-concept and social roles. ${ }^{26}$ The assumption that these three criteria are met during the disclosure of $B R C A 1 / 2$ test results led us to examine whether this event might be a teachable moment for inciting consultees to give up smoking. Cancer genetic testing has been reported to increase cancer worry among women belonging to families with hereditary breast/ovarian cancer, especially those found to be mutation carriers, whereas noncarriers were relieved of their worry. ${ }^{9,29}$ But whether an event is likely to be a teachable moment for inducing behavioral changes is thought to depend on the individual's subjective interpretation of the significance, cause, and meaning of the event. ${ }^{26}$ Because little evidence is available so far about smoking as a risk factor for breast cancer, the challenging results obtained here shed light on the fact that smoking may be marginally perceived as an overall threat in families with BRCA1/2 mutations. Fear of cancer in these families seems to be distinctly site specific rather than being perceived as an overall threat. Cancer diagnosis, cardiovascular events, and the discovery of pregnancy are known to be associated with the sudden cessation of smoking, ${ }^{26}$ but understanding how cancer-related worry contributes to creating a teachable moment for reducing multiple risk factors is still a challenging issue..$^{30}$

Only a few studies to date have focused on the impact of genetic testing on actual lifestyle risk behavior. Vassy et al. ${ }^{31}$ studied participants' intentions after presenting them with hypothetical scenarios about genetic testing for heart disease, type 2 diabetes, and stroke; those with a high risk of type 2 diabetes were found to be more motivated to make changes in exercise levels and diet than the other patients. O'Neill et al. ${ }^{32}$ studied diet and physical activity in 46 BRCA1/2 carriers and 23 definite noncarriers, without looking at their smoking habits. A few studies, mostly in the field of colorectal cancer, ${ }^{33-35}$ focused on reducing multiple cancer risk factors, including smoking. The latest technical developments in the field of genomic testing suggest that genomic test procedures will have to include the provision of multiple-risk information ${ }^{36}$ and that the issue of consultees' subsequent behavior is certainly a highly challenging one. ${ }^{37}$

Three of the main limitations of this study need to be discussed. First, nonparticipants were more frequently found to be smokers and to have higher cigarette consumption rates than participants (Table 1); second, the attrition rate may have affected the final results; and third, the recommendation not to smoke when breast reconstruction is performed after prophylactic mastectomy may have biased the results. ${ }^{19}$ To deal with the first limitation, we performed a sensitivity analysis including women who answered only the baseline questionnaire, using their baseline smoking characteristics to impute their subsequent habits during the follow-up period in order to determine whether this would affect the results, which was not found to be the case. To address the second limitation, we compared the last smoking practices of those who were lost/not lost during the 5 -year follow-up period and found no differences in the 0-, 6-, 12-, or 24-month consumption rates between those two groups; these results show that there was no selective bias in the outcome variable. Last, to address the third limitation, we checked that the decrease in the carriers' smoking practices observed here cannot be definitely attributed to undergoing risk-reducing mastectomy or to the indication of breast reconstruction. We also looked at the patients' alcohol consumption, which was significantly associated with their baseline smoking behavior but not with the changes in their smoking habits during the follow-up period.

In conclusion, this study of the smoking habits of unaffected BRCA1/2 carriers/noncarriers shows that no change in the prevalence of smokers occurred during the 5 years after the disclosure of these women's $B R C A 1 / 2$ test results. In the short term, however, the number of cigarettes smoked per day by BRCA1/2 carriers decreased significantly (by $20 \%$, on average) compared with that of noncarriers. The clinical significance of these results could be improved if the process of cancer genetic testing were regarded as an opportunity for conveying general information about both clinically significant lifestyle and genetic risk factors. Further studies will be required to elucidate the interactions between individuals' multiple preventive efforts in populations of this specific kind.

\section{ACKNOWLEDGMENTS}

This study was supported financially by the Institut National du Cancer (RPT08011AAA) and the SIRIC (grant INCA-DGOS-Inserm 6038), and the GENEPSO cohort was supported by "La Ligue 
Nationale Contre le Cancer." Special thanks are extended to the GENEPSO Psycho-Social Working Group, which was in charge of the project, and the French Cancer Genetic Network.

\section{DISCLOSURE}

The authors declare no conflict of interest.

\section{REFERENCES}

1. Pirie K, Peto R, Reeves GK, Green J, Beral V; Million Women Study Collaborators. The $21^{\text {st }}$ century hazards of smoking and benefits of stopping: a prospective study of one million women in the UK. Lancet 2013;381:133-141.

2. Ferlay J, Shin HR, Bray F, Forman D, Mathers C, Parkin DM. Estimates of worldwide burden of cancer in 2008: GLOBOCAN 2008. Int J Cancer 2010;127:2893-2917.

3. Bjerkaas E, Parajuli R, Weiderpass E, et al. Smoking duration before first childbirth: an emerging risk factor for breast cancer? Results from 302,865 Norwegian women. Cancer Causes Control 2013;24:1347-1356.

4. Budzinski EE, Patrzyc HB, Dawidzik JB, et al. Pyrimidine base damage is increased in women with BRCA mutations. Cancer Lett. 2013;338:267-270.

5. Lecarpentier J, Noguès C, Mouret-Fourme E, et al.; GENEPSO. Variation in breast cancer risk with mutation position, smoking, alcohol, and chest $\mathrm{X}$-ray history, in the French National BRCA1/2 carrier cohort (GENEPSO). Breast Cancer Res Treat 2011:130:927-938

6. Ginsburg O, Ghadirian P, Lubinski J, et al.; Hereditary Breast Cancer Clinical Study Group. Smoking and the risk of breast cancer in BRCA1 and BRCA2 carriers: an update. Breast Cancer Res Treat 2009;114:127-135

7. Meiser B, Gaff C, Julian-Reynier C, et al. International perspectives on genetic counseling and testing for breast cancer risk. Breast Dis 2006;27:109-125.

8. Bradbury AR, Ibe CN, Dignam JJ, et al. Uptake and timing of bilateral prophylactic salpingo-oophorectomy among BRCA1 and BRCA2 mutation carriers. Genet Med 2008;10:161-166.

9. Julian-Reynier C, Mancini J, Mouret-Fourme E, et al. Cancer risk management strategies and perceptions of unaffected women 5 years after predictive genetic testing for BRCA1/2 mutations. Eur J Hum Genet 2011;19:500-506.

10. Bostean G, Crespi CM, McCarthy WJ. Associations among family history of cancer, cancer screening and lifestyle behaviors: a population-based study. Cancer Causes Contro/ 2013;24:1491-1503.

11. Townsend JS, Steele CB, Richardson LC, Stewart SL. Health behaviors and cancer screening among Californians with a family history of cancer. Genet Med 2013:15:212-221.

12. Emmons KM, Kalkbrenner KJ, Klar N, Light T, Schneider KA, Garber JE. Behavioral risk factors among women presenting for genetic testing. Cancer Epidemiol Biomarkers Prev 2000:9:89-94.

13. Radloff LS. The CES-D scale: a self-report depression scale for research in the general population. Applied Psychological Measurement 1977;1:385-401.

14. Fuhrer R, Rouillon F. La version française de l'échelle CES-D [Center for Epidemiologic Studies-Depression Scale]. Description et traduction de l'échelle d'autoévaluation. Psychiatrie et psychobiologie 1989;4:163-166.

15. Min Y, Agresti A. Random effect models for repeated measures of zero-inflated count data. Stat Mode/ 2005;5:1-19.

16. Atkins DC, Baldwin SA, Zheng C, Gallop RJ, Neighbors C. A tutorial on count regression and zero-altered count models for longitudinal substance use data. Psychol Addict Behav 2013:27:166-177.

17. Agresti A. Categorical Data Analysis. 3rd edn. Wiley: Hoboken, NJ, 2013.

18. Diggle P, Heagerty P, Liang K, Zeger S. Analysis of Longitudinal Data. 2nd edn. Oxford University Press: Oxford, UK, 2002
19. Krueger JK, Rohrich RJ. Clearing the smoke: the scientific rationale for tobacco abstention with plastic surgery. Plast Reconstr Surg 2001;108:1063-1073; discussion 1074-1067.

20. Julian-Reynier C, Welkenhuysen M, Hagoel L, Decruyenaere M, Hopwood P; CRISCOM Working Group. Risk communication strategies: state of the art and effectiveness in the context of cancer genetic services. Eur J Hum Genet 2003;11:725-736.

21. Beck F, Guignard R, Richard J, Wilquin J, Peretti-Watel P. Augmentation récente du tabagisme en France: principaux résultats du Baromètre santé, France, 2010. Bulletin Epidémiologique Hebdomadaire 2011;20-21:230-232.

22. Martin J, de Launay $C$, Chauvin P. Conditions et évènements de vie corrélés au surpoids des adultes: une analyse par sexe des données de la cohorte SIRS, agglomération parisienne, 2005. Bulletin Epidémiologique Hebdomadaire 2010;4:28-32.

23. Beck F, Richard J. Epidémiologie de I'alcoolisation. EMC-endocrinologieNutrition 2012:1-9 (article 10-384-B-310).

24. Fu SS, van Ryn M, Sherman SE, et al. Proactive tobacco treatment and population-level cessation: a pragmatic randomized clinical trial. JAMA Intern Med 2014:174:671-677.

25. Marteau TM, Hollands GJ, Fletcher PC. Changing human behavior to prevent disease: the importance of targeting automatic processes. Science 2012;337:1492-1495.

26. McBride CM, Emmons KM, Lipkus IM. Understanding the potential of teachable moments: the case of smoking cessation. Health Educ Res 2003;18:156-170.

27. Lawson PJ, Flocke SA. Teachable moments for health behavior change: a concept analysis. Patient Educ Couns 2009;76:25-30.

28. Cohen DJ, Clark EC, Lawson PJ, Casucci BA, Flocke SA. Identifying teachable moments for health behavior counseling in primary care. Patient Educ Couns 2011;85:e8-15

29. Hamilton JG, Lobel M, Moyer A. Emotional distress following genetic testing for hereditary breast and ovarian cancer: a meta-analytic review. Health Psychol 2009;28:510-518.

30. McBride CM, Puleo E, Pollak KI, Clipp EC, Woolford S, Emmons KM. Understanding the role of cancer worry in creating a "teachable moment" for multiple risk factor reduction. Soc Sci Med 2008;66:790-800.

31. Vassy JL, Donelan K, Hivert MF, Green RC, Grant RW. Genetic susceptibility testing for chronic disease and intention for behavior change in healthy young adults. J Community Genet 2013;4:263-271.

32. O'Neill SC, Kaufman E, DeMarco T, et al. Changes in diet and physical activity following BRCA1/2 testing. J Psychosoc Oncol 2008;26:63-80.

33. Emmons KM, McBride CM, Puleo E, et al. Project PREVENT: a randomized trial to reduce multiple behavioral risk factors for colon cancer. Cancer Epidemiol Biomarkers Prev 2005;14:1453-1459.

34. McElwaine KM, Freund M, Campbell EM, et al. Clinician assessment, advice and referral for multiple health risk behaviors: prevalence and predictors of delivery by primary health care nurses and allied health professionals. Patient Educ Couns 2014;94:193-201

35. Hawkes AL, Chambers SK, Pakenham KI, et al. Effects of a telephone-delivered multiple health behavior change intervention (CanChange) on health and behavioral outcomes in survivors of colorectal cancer: a randomized controlled trial. J Clin Oncol 2013;31:2313-2321.

36. Graves KD, Leventhal KG, Nusbaum R, et al. Behavioral and psychosocial responses to genomic testing for colorectal cancer risk. Genomics 2013:102:123-130.

37. Grant RW, O'Brien KE, Waxler JL, et al. Personalized genetic risk counseling to motivate diabetes prevention: a randomized trial. Diabetes Care 2013;36: 13-19. 